\section{Effects of Ethirimol on Cytological Characters in Barley}

THERE is increasing evidence that chromosome size and mass are highly variable within a species. Both natural and induced variation in the DNA ${ }^{1,2}$ and protein ${ }^{3-5}$ content of chromosomes is known, and I have demonstrated a positive linear correlation between naturally occurring changes in the volume of metaphase chromosomes and the RNA and histone protein content of the nuclei of Vicia faba. The changes in chromosome volume were not accompanied by variation in the amount of 4C DNA. Similar changes are known to be induced by variations in the mineral content of a culture solution ${ }^{5}$, in temperature $^{7}$ and in the hormone balance of plants (personal communication from $\mathrm{N}$. Jones). It has been suggested ${ }^{5,6}$ that such changes within a species are correlated with the metabolic activity of the meristems in which they occur. To test this hypothesis, I have investigated the effects of ethirimol, which is known to affect root growth, on chromosome volume and root length. If the hypothesis is correct, ethirimol should affect both characters in the same way. Apart from the theoretical interest of such a study, it seemed useful to investigate any possible cytological effects of ethirimol, which may be used widely as a fungicide.

Ethirimol $^{8}$ (5-butyl-2-ethylamino-4-hydroxy-6-methyl pyrimidine) or 'Milstem' (ICI) is a white crystalline solid with a water solubility of $0.2 \%$ at room temperature. It acts as a systemic fungicide and is particularly effective against powdery mildew of barley (Erysiphe graminis DC. f. sp. hordei Marchal). When ethirimol is applied as a seed dressing it is released slowly from the soil during a long period so that small amounts are continually present in the plant. Such application thus gives long lasting control of mildew from germination until ear emergence. The fungicide is translocated in the xylem but not in the phloem and at normal rates of application is claimed not to be phytotoxic.

Three varieties of barley (Hordeum vulgare) -_Julia', 'Sultan' and 'Maris Otter'-were grown either in culture solution or in the field. In culture experiments seeds were germinated on moist filter paper and the resulting plants were transferred after 3 days to aerated modified Hoagland culture solution so that their roots were immersed. Ethirimol was added as a wettable powder to the culture solution and renewed weekly so that the concentration of ethirimol available to the plants throughout their life history did not vary. In the field experiment the concentration of ethirimol available may have varied widely during the life of the plant because the fungicide was applied only once, as a seed dressing.

In the first experiment 'Julia' plants were grown in culture solution with or without 16 p.p.m. of ethirimol in a glasshouse at $20^{\circ} \mathrm{C}$ with continuous light. After 2 weeks plants grown in the presence of ethirimol had much shorter roots than those grown without the fungicide, but there was no significant difference in shoot length (Table 1).

Chromosome volume was measured in well spread somatic metaphase plates in root tip squashes made from new root, less than $1 \mathrm{~cm}$ long. The total chromosome volume per cell in plants grown in the presence of ethirimol was $68 \%$ of that in plants grown without the fungicide (Table 1)-a highly significant difference. The observation that decreased root growth is accompanied by a decrease in chromosome volume

Table 1 Mean Length of the Longest Root and the Shoot and Chromosome Volume of 'Julia' Barley 2 Weeks after Germination

\begin{tabular}{cccc}
\hline $\begin{array}{c}\text { Ethirimol } \\
(\text { p.p.m.) }\end{array}$ & $\begin{array}{c}\text { Root } \\
(\mathrm{cm})\end{array}$ & $\begin{array}{c}\text { Shoot } \\
(\mathrm{cm})\end{array}$ & $\begin{array}{c}\text { Chromosome } \\
\text { volume }\left(\mu \mathrm{m}^{3}\right)\end{array}$ \\
0 & $20.75 \pm 0.52$ & $20.89 \pm 0.59$ & $185.1 \pm 2.36$ \\
16 & $10.98 \pm 0.20$ & $19.78 \pm 0.37$ & $126.4 \pm 3.05$ \\
\hline
\end{tabular}

The decrease in mean chiasma frequency in treated plants was between 2 and $4 \%$ in each case.

* Figures are the mean values for ten cells.
Table 2 Mean Chiasma Frequency

\begin{tabular}{ccccc}
\hline Experiment & Ethirimol & 'Julia' & 'Sultan' 'Maris Otter' \\
1 & 0 & $13.91 \pm 0.03$ & & \\
& 16 p.p.m. & $13.35 \pm 0.08$ & & \\
& 0 & $13.88 \pm 0.03$ & $13.92 \pm 0.02$ & \\
2 & 0.16 p.p.m. & $13.92 \pm 0.02$ & $13.78 \pm 0.02$ & \\
3 & 16.0 p.p.m. & $13.51 \pm 0.03$ & $13.64 \pm 0.05$ & \\
3 & 0 & & & $13.71 \pm 0.03$ \\
& 4 pounds/ & & & $13.46 \pm 0.03$ \\
\hline
\end{tabular}

supports the hypothesis that changes in the volume of metaphase chromosomes reflect the level of metabolic activity of the meristems in which they occur. The decrease in chromosome volume in roots treated with ethirimol does not necessarily indicate a specific effect of the fungicide on this nuclear character, but it probably reflects a toxic effect of the chemical on the growth rate of treated roots. It should be emphasized that a treatment of 16 p.p.m. of ethirimol is extremely large compared with the rate of application recommended by ICI. When the fungicide was supplied in a concentration of 0.16 p.p.m.much closer to the maker's recommendation-root and shoot growth increased.

Plants in the first experiment were grown until heading, after 10-11 weeks, and suitable inflorescences were then fixed. Table 2 shows that the fungicide significantly reduced chiasma frequency in pollen mother cells when plants were free from infection by powdery mildew throughout their life history.

In a second experiment 'Julia' and 'Sultan' barley plants were inoculated with powdery mildew (race C5, isolate B8 104) which attacked 'Julia' but not 'Sultan'. Plants of both varieties were grown in culture solution containing $0,0.16$ or 16 p.p.m. of ethirimol. Chiasma frequency in pollen mother cells was scored (Table 2). Both concentrations gave complete control of powdery mildew, although when no ethirimol was used only 'Julia' was infected with the fungus. There was no significant difference between varieties, and no interaction between treatments and varieties; the only significant difference was between treatments. There was a decrease in mean chiasma frequency in the pollen mother cells of plants treated with 16 p.p.m. of ethirimol, compared with untreated plants, whether infected with powdery mildew or not.

When, in the third experiment, 'Maris Otter' was grown in the field with 0 or 4 pounds/acre of ethirimol added as a seed dressing, there was again a small but highly significant reduction in chiasma frequency in the pollen mother cells of treated plants compared with untreated plants (Table 2). In this case the rate of application was four times greater than that recommended by $\mathrm{ICI}^{8}$.

The small reduction in chiasma frequency, even when ethirimol is supplied in large concentrations, indicates that losses in yield due to infertility are most unlikely as a result of fungicide treatment. Plant breeders and cytologists should, however, use ethirimol cautiously on experimental material if chiasma frequency is to be determined and on carly generations of genetically segregating material.

I thank ICI Ltd for supplying samples of ethirimol. Michael D. BENNETT

Plant Breeding Institute,

Trumpington, Cambridge

Received July 20; revised August 21, 1970.

1 Evans, G. M., Durrant, A., and Rees, H., Nature, 212, 697 (1966).

2 Burns, J. A., and Gerstel, D. U., Genetics, 57, 155 (1967).

3 Schrader, F., and Leuchtenberger, C., Exp. Cell. Res., 1, 421 (1956).

4 Gelfant, S., and Clemmons, J. J., J. Cell. Comp. Physiol., 46, 529 (1955).

5 Bennett, M. D., and Rees, H., Chromosoma, 27, 226 (1969).

6 Bennett, M. D., Chromosoma, 29, 317 (1970)

7 Darlington, C. D., and La Cour, L. F., Ann. Bot., NS, 2, 615 (1938)

8 Bebbington, R. M., Brooks, D. H., Geoghegan, M. J., and Snell, B. K., Chem. Ind., 1512 (1969). 